\title{
An Innovative Model to Promote CSR among SMEs Operating in Industrial Clusters: Evidence from an EU Project
}

Massimo Battaglia,* Lara Bianchi, Marco Frey and Fabio Iraldo

Sant'Anna School of Advanced Studies, Pisa, Italy

\begin{abstract}
This paper presents the findings of our EU co-funded project, an idea developed to better understand the opportunities to formalize corporate social responsibility (CSR) practices for small and medium enterprises (SMEs) in a clustered system. Small companies often have to compete in a global market; for this reason, cooperation among SMEs, and with local stakeholders and intermediary institutions, might be facilitated by a collective answer to new market requests. Cooperation and social capital are key elements to facilitate trust amongst involved local actors. Moreover, they can also play a key role in the formalization of CSR policies and practices for small companies. In our project, we aimed at identifying and understanding the role of the 'intermediary institutions' (such as trade unions, local authorities, business consortia) in the cluster. Throughout the paper, we focus on the analysis of three industrial clusters in Tuscany (Italy). Copyright (C) 2010 John Wiley \& Sons, Ltd and ERP Environment.
\end{abstract}

Received 16 October 2009; revised 4 January 2010; accepted 5 January 2010

Keywords: SMEs; CSR tools; industrial cluster; intermediary institutions

\section{Introduction and Theoretical Framework}

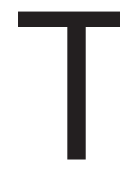

HIS PAPER FOCUSES ON THE IMPORTANCE OF CORPORATE SOCIAL RESPONSIBILITY (CSR)-RELATED TOPICS FOR SMALL and medium enterprises (SMEs) operating in industrial clusters.

In an SME, like in any other business organization, the efficiency and effectiveness of business activities are influenced by societal problems (Spence and Schmindpeter, 2003). The SME has a tight connection with the context in which it is located and this fact induces a strong development of CSR-related actions; each firm is, in this way, inclined to integrate local social and environmental issues in the business activity.

On the other hand, with respect to the CSR concept, according to the European Commission (200I) definition 'CSR is a concept whereby companies integrate social and environmental concerns in their business operations and in their interaction with their stakeholders on a voluntary basis.' As in other definitions of CSR, this one also emphasizes the close relationship between the organization's behavior and social/environmental issues. Thus, if it is proven true that in recent years CSR has become relevant in business studies, it is still necessary to better 
explain the way in which SMEs apply CSR (Thompson and Smith, I99I; Spence, I999; Observatory of European SMEs, 2002; Perrini, 2006; Perrini et al., 2006; Spence, 2007).

During the past decades, literature and research have identified some common characteristics of SMEs. They have very heterogeneous sizes and organizational structures. They are owner-managed and not very bureaucratic out of necessity to solve day-to-day problems. They have similar financial turnover and informal relations and communication process. They recognize the importance of interpersonal relationships and have a high interrelation with the local community and the local environment. They often operate in a local network of SMEs and/or in a local supply chain or a large enterprise's network of suppliers (Spence, I999; Lepoutre and Heene, 2006; Murillo and Lozano, 2006). These characteristics underline a deep difference between large and small/medium firms which can be often linked to the presence of social capital in a specific context. This element facilitates the use of informal CSR policies adopted by SMEs (Chiesi, 2005; Perrini et al., 2007; Russo and Tencati, 2009), a process also known as 'implicit CSR' (Matten and Moon, 2004; 2008), or 'silent CSR' (Jenkins, 2004). As Perrini (2006) emphasizes, whilst large enterprises interpret CSR as a multistakeholder approach, in SMEs, CSR practices are based on synergies and relationships between different subjects; i.e., they are based on social capital. The concept of social capital is generally associated with the intangible assets of reputation, trust, legitimacy and consensus (Putnam et al., I993; Spence et al., 2000; Tilley, 2000; Adler and Kwon, 2002; Spence and Schmindpeter, 2003; Habisch et al., 2005). Socially responsible behaviors are often able to originate and endorse trust links between different actors: this represents the basis of the long-term performance of SMEs embedded in the local communities in which they operate.

If it is true that the use of informal CSR is very common among SMEs, the transition toward a formalized CSR, on the other hand, is often very difficult. The lack of human, technical and organizational resources found in SMEs makes the implementation of formalized CSR policies very difficult, both because of the perceived costs and the complexity of the operation (European Commission, 2002; 2004; Luetkenhorst, 2004; Fox, 2005; Lepoutre and Heene, 2006). An investment in CSR is often considered hard and uncertain: hard because the enterprise needs to find resources for it; and uncertain because there is not enough empirical evidence explaining the benefits achieved by social responsibility strategies. Moreover, enterprises perceive CSR as a complex business issue that requires a specific expertise.

On the basis of the results of our EU Project, this paper proposes a way to overcome these difficulties and remove the barriers to the adoption of CSR-related tools. Our approach is based on the idea that the barriers faced by SMEs can be overcome in a networked system, called a 'cluster', in which companies tend to operate as a metaorganization (Spence, I999). In a cluster, social capital is strengthened by the proximity of firms, the availability of local resources, and close correlation with local institutions. For this reason, an industrial cluster is defined as a geographically proximate group of interconnected enterprises and associated institutions (Porter, I998). As the literature posits (Piore and Sabel, I987; Becattini, I989; I990; Piore, I99I; Ferrucci and Varaldo, I996; I997) the cluster organizational structure and culture are characterized by the presence of a relational environment, built on systematic relationships among local actors. This allows the sharing of a collective identity based on common values, also with respect to the way the business is run. In an industrial cluster, SMEs have similar social and environmental impacts; the firms have similar interactions with local actors; and they often face common social and environmental pressures from stakeholders. It is possible to reduce the costs of action and to improve the results for each firm with a clustered management approach to these issues (European Commission, 2007). Therefore, high concentration of SMEs with similar production processes often causes significant social and environmental problems. This requires integrated management in order to prevent accumulated negative externalities on CSR-related issues. The management of CSR through the cluster can enhance the possibility of defining common effective policies and strategies, and it can improve relations with the local stakeholders (community, institutions, control bodies, etc.).

From this point of view, an active role in the cluster system could be played by the so-called 'intermediate institutions', such as trade associations, business consortia, chambers of commerce (European Commission, 2007; Frey and Iraldo, 2008). Intermediate institutions are defined 'intermediate' since they operate among firms, local communities, local economies and local politics. These institutions have a primary role in industrial clusters, with reference to the integration of local and social values (Trigilia, I99I). In addition, intermediate institutions facilitate the improvement of communication between local communities and firms, and the innovation processes on a 
cluster scale (Arrighetti and Serravalli, I999; Dei Ottati, 2002; Visser and Atzema, 2008). Finally, they influence the promotion of shared strategies to tackle common problems at cluster level, in the environmental field, for example (Iraldo, 2002; Montini and Zoboli, 2004). Therefore, intermediate institutions could also play a key role in the implementation and diffusion of CSR policies among the cluster firms.

\section{Research Design}

Our research is based on the experience of the COOPERATE Project (COmpanies OPErating in a Responsible Area and with Transparent Ethics), co-financed by the European Commission (DG Enterprise \& Industry) within the Mainstreaming CSR among SMEs EU Program. The aim of the research was to promote and to spread CSR concepts, practices, and tools among SMEs operating in industrial clusters in the Tuscany region (Italy). The project relied on strong, consolidated and trusted information channels and knowledge-sharing networks and it emphasized CSR-oriented business strategies as a relevant competitive opportunity for SMEs. Our research involved three Tuscan industrial clusters: the Capannori (LU) paper cluster, the Santa Croce s/Arno (PI) tanning cluster, and the Empolese-Valdelsa (FI) clothing cluster. In each cluster, an innovative approach for cooperative CSR management was proposed, based on the role of local 'intermediary institutions and organizations'. A number of industrial (SMEs) and non-industrial organizations (e.g., trade associations, local authorities, service providers) selected, adapted and developed a series of CSR 'formalized' practices and tools, relying on some cooperative and collective actions, with the goal of defining a new method for mainstreaming CSR among SMEs. As a first step, a working group was created in each cluster with the goal of designing and implementing a territorial cooperative approach to CSR:

- In the tannery cluster, five actors participated (i.e., three local business associations, the representatives of the main local trade union and the provincial local authority).

- In the clothing cluster, there were seven participants (i.e., the local development agency, the local public authority representative of ten municipalities, three local business associations, the local office of Regional Environmental Protection Agency, and a local sectorial trade union).

- Finally, in the paper cluster, four members took part in the research (i.e., the bureau of Lucca Province, the main local business association, the local Paper Cluster Committee and the local Chamber of Commerce).

In each working group, the Sant'Anna School had the role of scientific expert. In each cluster, the composition of the working groups was different, due to the differences in the three productive sectors. The tanning and clothing clusters are mostly composed of small and micro-enterprises operating in fragmented supply chains (Dunford, 2003; Nordas, 2004; IFM, 2007), whose representatives are the artisans associations (not only the industrial ones). On the other hand, the paper cluster is composed of medium-sized enterprises, represented only by industrial associations. Many activities were carried out in the project; the most important in terms of research results were the following three: the drafting of the Sustainability Report of the Cluster, the identification and dissemination of CSR tools for individual SMEs, and, finally, the organization of a thematic focus group.

\section{Findings}

The Sustainability Report is a document specific to a cluster summarizing the findings of direct interviews with firms and local actors. The report is concerned with the social, economic and environmental performance of the cluster. A special panel of indicators shared by each working group measured these performances. The utility of the Sustainability Report is multifaceted and relates to both the overall size of the cluster and the individual SMEs. In particular:

- In terms of the overall cluster: the report allowed for the definition of a set of indicators for each territory to measure its economic, social, and environmental performance. The document highlighted the strategic position 
of each cluster with respect to the three principles of sustainability. It also represented a first opportunity to study the relationships between public and private actors in the cluster on sustainability-related issues. In addition, it was an important experience to provide third parties with information about the cluster dynamics. Finally, the collected information provided opportunities for local working groups to determine the needs of SMEs with respect to CSR tools.

- In terms of the single SME: the report provided an aggregated overview of social and environmental performances. This represented a benchmark for each firm evaluating its path toward the adoption of CSR tools. It could be considered as a sort of local average value performance.

There were 92 companies directly involved in the interviews on which the report was based. The questions mainly concerned the level of awareness of CSR issues; the presence of ethical/environmental certifications; the identification of local key stakeholders; information about the organizational structure; and information on employee training. A report was drafted in each cluster.

From the results of the interviews, it was possible to draw some interesting findings:

- In all clusters, employees and clients were identified as privileged stakeholders for the firms. This fact underlines not only the importance of clients from a commercial point of view, but also recognition of the importance of workers as a factor to stimulate increased productivity.

- In the fashion system (tanning and clothing), suppliers were also considered important stakeholders. On the other hand, in the paper industry communities and local government institutions roles were also relevant.

- These findings were confirmed as part of the answers concerning corporate value systems, in which the majority of respondents focused on the health and safety of their workers, production, and, for tanneries and paper mills, environmental protection.

- The knowledge of and the level of diffusion of CSR tools were very different for the three clusters, as well perceptions of their utility. In the clothing industrial cluster, a rather low number of firms held certification, and a lack of knowledge of these tools (except for the national INAIL standard, Ecolabel, and ISOI40or certification) was evident. On the contrary, in the paper cluster, the level of knowledge of management standards and reporting tools was particularly high. Finally, in the tanning cluster, the level of knowledge of CSR tools was much higher in the tanneries than for third party contractors.

- In terms of preferences for CSR tools, a prevalence of management tools with respect to reporting tools was expressed. In particular, the fashion firms had a general orientation in favor of management systems complying with SA8000/EMAS. On the other hand, the paper producers focused more on the issue of employee health and safety.

- In the fashion industry, weak concerns emerged regarding the perception of benefits associated with CSR tools, especially in a short-term strategy.

- With regard to the firms that already adopt CSR tools, external pressures were identified as one of the main reasons for their decision in both the clothing and the paper clusters.

Based on evidence emerging from both interviews and collected performance indicators, the working groups identified and implemented a series of actions aimed at encouraging the spread of CSR tools among SMEs. First, the working groups organized training and informative activities for SMEs about the benefits linked to the implementation of management systems in accordance with international standards (with particular attention to the ISOI400I/EMAS, OHSASı800I and SA8000 standards). Overall, 26 firms participated in the training/informative initiatives. In the Santa Croce and Empoli clusters, the working groups identified the need for drafting a guideline document, which they distributed among businesses. This document outlined the requirements of environmental certification schemes (ISOı400I/EMAS), the patterns of ethical certification (SA8000), and the possible ways of their implementation within the clothing and tanning sectors. In the Capannori cluster, procedural schemes to assist the integration of environmental and safety management systems were established and diffused among local enterprises.

From a research perspective, these initiatives demonstrated the feasibility of collective action at cluster level and showed the existence of a local relational system that could support their implementation. 
To these initiatives, which have operational and informative value, we can add a third type tested under the project; i.e., activities carried out in ten sample companies oriented to experience the adoptability of CSR tools directly. Four companies were involved in the clothing sector, three in paper mills and three in the tanning sector. We visited each company a few times with the purpose of providing information about the gap between the firm's performance and CSR standards. Then we investigated the perceived barriers to the adoption of CSR-formalized tools. In this phase of the project, we confirmed some of the difficulties that had emerged during the interviews. In particular, SMEs from the tanning and clothing clusters pointed out two critical aspects relating to the adoption of CSR tools: high costs and complex bureaucracy. Secondly, it was stressed that the perceived short-term benefits are still very few, mainly due to end-market preference for low prices over CSR principles. A possible solution could be to simplify the adoption of formalized CSR tools, which would meet the needs of local firms. Finally, with regard to the issue of local competition, a specific issue emerged from the meetings: the companies expressed concern about the increasing risk of unfair local competition that can be induced by the opportunistic behavior of some firms that push their suppliers to drastically lower their prices at the expense of products and processes quality. This phenomenon is dangerous because it undermines the trust that keeps local relationships from falling apart. An approach that seeks to disseminate tools for transparency between companies, such as CSR, can help limit these risks.

The latest initiative of our project that deserves particular attention was the organization of a thematic focus group to detect the point of view of internal and external stakeholders with reference to a cluster approach to CSR.

Thirty-eight people participated at the event. The participants were classified into three categories:

I. Eight trade associations representing the cluster firms.

2. Twelve subjects representing banks/insurances and market actors operating in the characterizing sectors involved in the project.

3. Eighteen external stakeholders (institutions, associations, trade unions, NGOs, etc.).

Each participant was asked to express his preferences in ten closed questions with predefined answers. We now report the series of findings and considerations that emerged from this consultation:

- The importance of developing CSR practices within the policies and strategies of clusters was unanimously highlighted. Maintaining competitive positions in the market and the need for ensuring regulatory compliance are two key reasons for adopting CSR practices (with more than 50\% consensus), as recognized by the representatives of SMEs themselves. The ease of access to finance is also an important stimulus, but more for stakeholders, such as banks, insurance companies and institutions, than for SMEs. This highlights the need to effectively promote these tools from an operative point of view, rather than only by means of co-financing.

- With reference to the reasons why SMEs perceive that CSR tools are not necessary, indications from the stakeholders focused on the excessive complexity and costs of the tools (34\%).

- Regarding internal difficulties faced by SMEs in the development and implementation of CSR practices, a lack of top management on cultural CSR emerged from the stakeholders $(40 \%)$. This indication highlights an important problem related to the cultural and knowledge growth of organizational leadership as the main obstacle, followed by the lack of resources and expertise (27\%) and the scant knowledge of CSR tools (25\%). From these indications, the need to stimulate the spread of a new managerial culture amongst SMEs emerged.

- With regard to the different ways of supporting the adoption of CSR tools by SMEs operating in clusters, there was a particular focus on the issue of administrative and normative simplification (24\%), and toward the development of cluster tools $(27 \%)$, in a framework of cooperation and sharing of experiences and approaches. The definition of collective instruments seems to be the most viable path, alongside initiatives of public decisionmakers that can enable SMEs to receive short-term benefits related to the development of CSR instruments. Local institutions are identified by the stakeholders (34\% of preferences) as those who should increase their support of SMEs in the development of CSR practices at the cluster level. 


\section{Conclusions}

\section{Cluster Approach to CSR and its Benefits}

This paper aims to show that the proposed cluster approach allows the achievement of sustainable objectives and the adoption of CSR-related tools by SMEs. This is made possible by the set up of specific cluster tools: local multistakeholder working groups, communication tools to disseminate expertise and best practices, operational models, guidelines to support organizations toward CSR, and audits at the local level. The cluster approach is based on a methodology by which the CSR tools are developed by a local productive system as a whole and not simply by the enterprises it is made up of. In other words, the traditional approach to CSR at the local level among SMEs proposes the promotion of sustainability management within the productive system, while our 'cluster' approach promotes CSR of the productive system.

The experience of the COOPERATE project showed that the results of the proposed cluster approach are intimately linked to the characteristics of the cluster in the relational environment. This is made possible by a number of synergies at the managerial and technological level to promote the inclusion and diffusion of innovative elements based on the partnership between the different firms operating within a cluster. Some results of a cluster approach can be identified with reference to different levels of analysis: the macro level is connected with the relations external to the cluster; the meso level, refers to the relations implemented inside the cluster; and, finally, the micro level, which is the point of view of the organizations operating in the cluster.

From the macro level, we notice that the benefits connected with CSR management at the individual firm level can be strengthened and amplified if CSR is applied at the territorial level to an entire industrial cluster. This aspect can positively affect the opportunities related to a global ethical and green supply chain management (Walton et al., I998; Carter, 2000; Theyel, 200I). The industrial clusters of traditional sectors (such as clothing and tanning) are today competing in national and international markets. In this global competitive arena, diversification emerged in the COOPERATE experience as a potential strategic variable (as shown in the focus groups, or in the opinion of leader SMEs) and the territorial characterization of a new strategic opportunity (e.g., a territorial brand). Therefore, the promotion of CSR policies and actions at the cluster level - as proposed in this paper - can improve the image of the cluster brand and, consequently, the competitive capability of many SMEs located in the same territory.

From the point of view of the cluster's internal relations (meso level), the application of a cluster approach to CSR can improve the management of social and environmental cumulative impacts caused by the concentration of a large number of SMEs operating in the same sector/territory (Iraldo, 2002; Frey and Iraldo, 2008). The cooperative nature of the approach proposed in this paper, in fact, prevents these impacts being undermined or not managed at all. Furthermore, there is a waste of resources in the territory, since the different actors implement actions individually to manage the 'cumulative' effects. At the meso level, the cluster approach promotes cooperation and the consequent use of common resources. In many cases, this is developed with the contribution of all the cluster's organizations, such as the Cluster Sustainability Report. It can also generate an improvement in the awareness of social and environmental topics, not only by the organizations operating in the cluster but also by the local community and public actors.

Finally, from the point of view of the organizations operating in the local productive system (micro level), the application of the cluster approach resulted in a fundamental instrument to overcome the barriers that prevent them developing systematic CSR initiatives (costs and complexity of the operation). SMEs involved in the project clearly expressed this need, and the opportunity of a coordinated approach was identified as interesting with positive effects perceived from both economic and organizational points of view.

The cooperative approach proposed in the COOPERATE project can help exploit the opportunities to share, the burden of innovation and development within the cluster, interacting with the same public authorities and social stakeholders. The proposed approach can also improve the coordination of the management of CSR-related issues (diversity management, health and safety of the workers, guarantees on child labor or illegal subcontracting, waste separation, collection and recovery, water sewage collection and purification, etc.) and of specific production phases (supply-chain management, investment planning, common audits, etc.). 


\section{Moving Toward a Formalized Cluster Approach to CSR}

The experience of the COOPERATE project also showed some elements that have to be carefully considered in order to guarantee the effectiveness of the approach. First of all, strong and legitimized leadership at local level is needed while proposing and managing the cooperative approach to CSR: the creation of policies and instruments at the cluster level has to be guided by a group of local intermediary institutions whose actions and promotions can be considered innovative by the local enterprises. Another relevant aspect is connected to the existence of common social and environmental problems to be managed at the cluster level. This aspect was clear, for example, in the paper cluster in Lucca, where the interest in a common approach to safety management represented the basis for a large participation in common initiatives promoted at local level. The proposed approach, in fact, strongly relies on the hypothesis that a set of organizations located in the same local context, operating in the same sector or supply chain and having the same stakeholders, face a large number of common social and environmental problems. In some cases, this is not completely true (for example, when the number of common impacts are the least important ones, while the most relevant ones are firm-specific) so the identification of common resources (models of procedures, training initiatives, etc.) can be extremely hard and, consequently, the cluster approach would have poorer results. Finally, as it emerged in all the clusters characterized by small enterprises, the benefits for firms of a cluster approach are evident, but not those deriving from the implementation of CSR tools. The firms perceived the opportunities of a cooperative approach and they demonstrated integration with local communities but, on the other hand, they expressed the need to receive short-term benefits from a formalized CSR approach.

Therefore, in opposition to a series of benefits that emerge from the experience of COOPERATE, we also note a number of critical factors that should be considered at the working group level in order to limit the extent and effectiveness of the approach. From this point of view, it is considered that, in our opinion, the definition of a formal model of a cluster approach could reasonably maximize the benefits and to respond to the real needs of local businesses. This formalization, based on what emerged in our research and from other research specific to the environment (Frey and Iraldo, 2008), can be described in five main phases.

The first phase should be the constitution of local working group, which represents the interests of the public and private sector, and should guide the creation of the entire process. The drafting of an initial declaration of intent (CSR policy), which may take the form of a voluntary agreement between the parties is desirable, in order to outline a course of work for the following years. The second step of the approach should be the study of the local cluster and its internal relationships between business and externally, from an economic, social and environmental standpoint. At this stage, the following aspects are important: the definition of a set of performance indicators and the direct and indirect recognition of the needs of local SMEs with respect to CSR. The collected information should constitute a document of analysis and social/environmental reporting, that could be made public. The third step would be the definition of a formalized program of initiatives geared toward the implementation and dissemination of CSR tools to the SMEs of the cluster, (e.g., through collective training, documentation management support, conduction of internal audits, identification of possible simplifications and economic benefits for businesses, etc.). Moreover, the construction of an external communication plan is important to enhance the social-economic performance of the cluster. The fourth step is to implement the previous phases. At this stage, a series of cluster indicators relating to the overall performance of CSR should be monitored. These indicators represent the basic element for the fifth and final phase, i.e., the follow up, in which the working group should monitor the effectiveness of initiatives implemented, possibly redefining new ones.

The approach described above, which outlines a circular managerial PDCA (Plan, Do, Check, Act) path, could reasonably assure the continuity of local initiatives and ensure a good spread of CSR tools among SMEs in the cluster. For the future, the capability of the three clusters to continue the promotion of CSR-related initiatives at local level is considered essential in order to fully assess the effectiveness of the approach.

In terms of future outlook, the research finally opened the possibility of investigating an important aspect for SMEs: the relationship between competitiveness and CSR. This is true in particular for SMEs operating in traditional manufacturing sectors, which are among the most affected by competition from developing countries. The possible competitive advantage is a central element for the Commission's new program, Responsible competitiveness: fostering corporate social responsibility in European industrial sectors, from which it will be interesting to assess what results emerge. 


\section{References}

Adler P, Kwon SW. 2002. Social capital: Prospects for a new concept. Academy of Management Review 27(I): I7-40.

Arrighetti A, Seravalli G (eds). I999. Istituzioni intermedie e sviluppo locale. Donzelli: Rome, Italy.

Becattini G. I989. Modelli locali di sviluppo. Il Mulino: Bologna, Italy.

Becattini G. I990. The Marshallian District as a socio-economic notion. In Industrial sectors and interfirm cooperation in Italy, Pyke F, Becattini G, Sengenberger W (eds). ILO: Geneva, Switzerland.

Carter CR. 2000. Ethical issues in international buyer-supplier relationships: a dyadic examination. Journal of Operations Management I8(2): I9I-208.

Chiesi AM. 2005. L'importanza della fiducia e del capitale sociale per la CSR. In Guida critica alla responsabilità sociale e al governo di impresa, Sacconi L (eds.). Bancaria editrice: Milan, Italy.

Dei Ottati G. 2002. Social concertation and local development: The case of industrial districts. European Planning Studies February, Io(4): $449-466$

Dunford M. 2003. The changing profile and map of the EU textile and clothing industry. University of Sussex, Falmer: Brighton, UK.

European Commission. 200I. Green Paper: promoting a European framework for Corporate Social Responsibility. COM (200I) 366: Brussels.

European Commission. 2002. European SMEs and social and environmental responsibility. Enterprise Publications: Belgium.

European Commission. 2004. European multistakeholder forum on CSR - Report of the round table on 'fostering CSR among SMEs'. EC: Brussels.

European Commission. 2007. Opportunity and responsibility. How to help more small businesses to integrate social and environmental issues into what they do. EC: Brussels.

Ferrucci L, Varaldo R. 1996. The evolutionary nature of the firm within industrial districts. European Planning Studies February, 4(I): 27-34.

Ferrucci L, Varaldo R (eds). I997. Il distretto industriale tra logiche di impresa e logiche di sistema. FrancoAngeli: Milan, Italy.

Fox T. 2005. Small and medium-sized enterprises (SMEs) and corporate social responsibility: a discussion paper. International Institute for Environment and Development (IIED): London.

Frey M, Iraldo F (eds). 2008. Il management dell'ambiente e della sostenibilità oltre i confini aziendali. FrancoAngeli: Milano.

Habisch A, Jonker J, Wegner M, Schmidpeter R (eds). 2005. Corporate social responsibility across Europe. Springer: Berlin-Heidelberg.

Institute Francaise de la Mode (IFM). 2007. Study on the competitiveness, economic situation and location of production in the textiles and clothing, footwear, leather and furniture industries - Final Report. Institute Francaise de la Mode: Paris, France.

Iraldo F. 2002. Ambiente, impresa e distretti industriali. FrancoAngeli: Milan, Italy.

Jenkins HM. 2004. A critique of conventional CSR theory: An SME perspective. Journal of General Management Summer 29(4): 37-57.

Lepoutre J, Heene A. 2006. Investigating the impact of firm size on small business social responsibility: A critical review. Journal of Business Ethics September 67(3): 257-273.

Luetkenhorst W. 2004. Corporate social responsibility and development agenda: the case of actively involving small and medium enterprises. Intereconomics 39: I57-166.

Matten D, Moon J. 2004. A conceptual framework for understanding CSR. In Corporate social responsibility across Europe, Habisch A, Jonker J, Wagner M, Schmidpeter R, (eds). Springer: Berlin; 335-356.

Matten D, Moon J. 2008. 'Implicit' and 'explicit' CSR: A conceptual framework for a comparative understanding of corporate social responsibility. Academy of Management Review, 33(2): 404-424.

Montini A, Zoboli R. 2004. Environmental impact and innovation in industrial districts. In Inside the industrial district. The evolution of local capitalism in Italy, Cainelli G. e Zoboli R. (eds). Physica-Verlag: Heidelberg.

Murillo D, Lozano JF. 2006. SMEs and CSR: An approach to CSR in their own words. Journal of Business Ethics September 67(3): 227-240.

Nordas HK. 2004. The global textile and clothing industry post the agreement on textile and clothing. WTO: Geneva.

Observatory of European SMEs. 2002. European SMEs and social and environmental responsibility, European Commission $2002 /$ no. 4.

Perrini F. 2006. SMEs and CSR theory: Evidence and implications from an Italian perspective. Journal of Business Ethics September 67(3): 305-316.

Perrini F, Pogutz S, Tencati A. 2006. Corporate social responsibility in Italy: State of the art. Journal of Business Strategies 23(I): 65-9I.

Perrini F, Russo A, Tencati A. 2007. CSR strategies of SMEs and large firms. Evidence from Italy. Journal of Business Ethics February 74(3): $285-300$.

Piore MJ. I991. L'opera, il lavoro e l'azione: l'esperienza dell'opera in un sistema di produzione flessibile. In Distretti industriali e cooperazione tra imprese in Italia, Pyke F, Becattini G, Sengenberger W (eds.). Quaderni Studi e Informazioni 34, Banca Toscana: Firenze.

Piore MJ, Sabel C. I987. Le due vie dello sviluppo industriale. Produzione di massa e produzione flessibile. Isedi: Milan, Italy.

Porter ME. I998. Clusters and the new economics of competition. Harvard Business Review 76(6): 77-90.

Putnam RD, Leonardi R, Nanetti R. I993. Making democracy work: Civic traditions in modern Italy. NJ Princeton University Press: Princeton, NJ.

Russo A, Tencati A. 2009. Formal vs. informal CSR strategies: Evidence from Italian micro, small, medium-sized, and large Firms. Journal of Business Ethics March 85: 339-353.

Spence LJ. I999. Does size matter? The state of the art in small business ethics. Business Ethics: A European Review 8(3): I63-I74.

Spence LJ, Jeurissen R, Rutherfoord R. 2000. Small Business and the environment in the UK and the Netherlands: toward stakeholder cooperation. Business Ethics Quarterly Io(4): 945-965.

Spence LJ, Schmidpeter R. 2003. SMEs, social capital and the common good. Journal of Business Ethics June 45(I/2): 93-Io8. 
Spence LJ. 2007. CSR and small business in a European policy context: The five 'C's of CSR and small business research agenda 2007. Business \& Society Review Winter II2(4): 533-552.

Theyel G. 200I. Customer and supplier relations for environmental performance. Greener Management International 35: 6I-69.

Thompson J, Smith H. I99I. Social responsibility and small business: suggestions for research. Journal of Small Business Management 29(I): $30-44$.

Tilley F. 2000. Small firm environmental ethics how deep do they go? Business Ethics: A European Review 8(I): 3I-4I.

Trigilia C. I99I. Il lavoro e la politica nei distretti industriali della Terza Italia. In Distretti industriali e cooperazione tra imprese in Italia, Pyke F, Becattini G, Sengenberger W (eds). Quaderni Studi e Informazioni 34, Banca Toscana: Firenze.

Visser EJ, Atzema O. 2008. With or without clusters: Facilitating innovation through a differentiated and combined network approach. European Planning Studies October 16(9): II69-II88.

Walton SV, Handfield RB, Melnyk ST. I998. The green supply chain: integrating suppliers into environmental management process. International Journal of Purchasing and Materials Management 34(2): 2-II. 